\title{
稀土元新的工業急义
}

\author{
Б. И. 柯 岡
}

（苏联科学院桸有元素矿物学、地球化学及結晶化学研究所）

最近五、尖年来，在稀土工業中發生了根本的变 化。稀土元素的技术应用的領域和范葍扩大了, 稀土 元素在鋼鉄冶金和特殊合金中获得了特品的地位，在 軍事和原子技术中出具有重要的意义。許多国家都以 很快的速度来發展稀土原料的开采和化学冶金方面的 稀土产品的生产。开始了各种新型矿石的开采和許多 新型化合物的生产。最主要的是, 出現了一个新的趋 向一一就是把混合的稀土元素分离成各种純的稀士金 亚，分别研究每种金猲的物理、化学和技术的性質，
井对其中每一种金屬的单独利用方式加以探討。

稀土元素一一般是混合物，有时也呈純金感及 其化合物的状态一一在黑色治金、有色治金、輕合金 的熔炼、原子能技术、玻璃工業、陶瓷及耐火材料工 業、照明技术、电子学及無綫电工業、化学工業, 以 及軍事技术中获得了各种各样的应用。

現代的稀土元䋜的工業应用見表 1 。表中所列举 的有些是目前台未实現, 而将来有可能实現的。

到不久以前为止，我們关于稀土元素怎样影响鎡

表 1 稀土金屬及其化合物目前和将来的工業应用范園

\section{1. 原子能技术}

抗故射綫的策皮㻦。耐久的原子能 电池，使用鉃-147 的錬便原子能电池。 含鈲 -170 的烼便透視机。其他作操伤和 医序用的放射性局位素。保护登和耐火 屈。用来吸收中子。用来分离鈎 -235

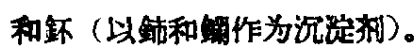

\section{4. 有色治金}

铜及銅合金的变形及瞅成合金。中

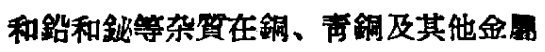
和合金中的有害影响。还原皓、钽、鈦及

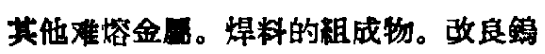
的机琙性能。

\section{7. 电子学和無織电技术}

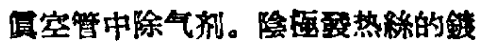
怑。不变黑的验玻理。作为电介筧和鉄 电体。放射体。

\section{8. 化学工業}

电光梓、照明彈、㜔英彈中的遇空 七即自燃的合金。清除倩珄气体。有机 和無机反应过程的催化狗。料、染料 及油的輔助成分，特別是作为干嬠刋。 使埕树不部色的有机化合物。

\section{2. 黑色治金}

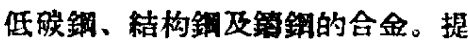
高䣄鉻合金的耐热栍。增加高电阻合全 的耐久性及汧腐蝕性。改良加热情况下

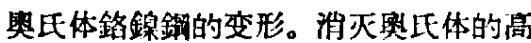
合金銈及复合金鋼的先天热脆性。把鉻

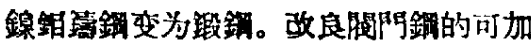
工性。获得高强度的球墨鎊鉄。用于装 甲鎆的新的磁合金。

\section{5. 玻璃，陶资及搹火材料}

玻㻦和登器的上色、玻琌的脱色和 提高透明度。滤光器。吸收紫外綫的、 通过紅外綫的和不受太晹光影响的光学 玻琌。特殊的光学皮琌。感光皮㻦。捱

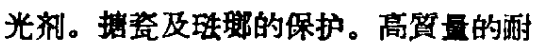
火材料。

\section{9. 军社技术}

烟慕。可爆炸物贫，原子能电池; 飞机秥构用的軖合金; 遇空气即自燃的 合金; 探照奵用的灼热碳; 燐; 軍事光 学仪器用的特殊媓㻦，战伤外科用的铄

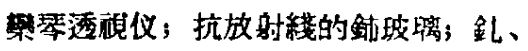

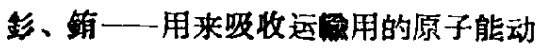
力装置中的中子。

\section{3. 輕合金}

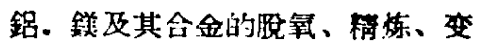
形及制成合金。飞机結构用的钻鋁合

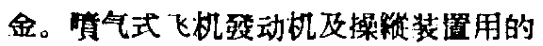

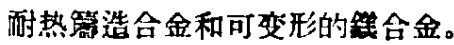

\section{6. 照明技术}

焰弧和高强度电弧（用于巨大的軍 事探照灯、指电影所用弧光灯、灯塔、 电影放映机、电視、医疗灯) 的电接(妁 热的碳)。軍事技术、电䤄、無䋐电㗎

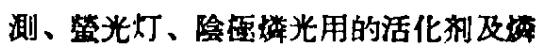
基。

\section{0. 其他方面}

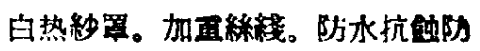
蛙的織物。浸清过滤布(使具有防的

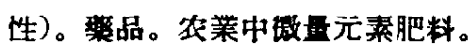

的性能的知識还是極其缺乏而互相矛盾的, 稀土元素 的工業应用也很微不足道。現在情况不一样了。由于 大量的試驗研究工作，确立了稀士:元素应用的几个極 重要的方向。在美国，实际上已經大規模地把稀土元 素应用到炼銅生产过程中去。在英国，有成效的工作
也曾不止一次地被提到，这些工作佾未發表，显然他 們是保哔的。在法国、瑞典及許多其他国家奴这一閒 題也愈来愈感兴趣了。

很大一部分的研究工作是混合稀士合金 ${ }^{[1]}$ j $j$ 面 的，但是除了稀土金显的这种混合物以外，还試险了 
含铜較多的、完全不含鈰的（然而合有所有其余的稀 土元素)、稀土元素呈局部氧化的和氧化銝的合金。

稀士元素加到黑色金㹇中去以后，可以起强烈的 还原剂的作用，有时也是卓絕的去气剂和胫硫剂; 此 外, 稀土元素可以提高流动性，在許多情况下，还可 以改善金屈的結构、金屬的机械和鋧造性能、可焊性 和在加热状况下的易切削性。

稀土元素在鋞鉄中表現出十分活潑的球化剂作 用。一般在熔炼超硬質球墨鑄鉄[?]时，为了經济的原 因，都用較便宜的鎂作为球化剂，但是鎂有一个缺点， 就是它不能抵消釷、鈦、鉛及其他杂質的影响，这些东 西桱常存在于鑄鉄中, 阻碍球状石墨在鑄鉄中的形成。 为此可以在鉡之外另加稀土元素，只要加入 $0.01 \%$ 的 数量就足以完全消灭上述混合物的有害影响。把鉄和 鈰(或混合稀士合金)闹时加到合金里去，显然是有利 的，因为这样可以同时减輕或避㣻鎂和鋪（或混合稀 土合金)的缺点一一混合稀土合金的成本很高, 鋘容易 爆炸。

加入稀士元素可以提高低碳鋼在空温下的展性, 无其重要的是提高低碳鋼在很低温度（零下）下的展 性。在用这种鋼軋制銅管时, 如果加入一些稀士元素, 就可以减低原品等; 在初㜞机中軋鋼时，根据美国的 生产实践的材料, 加稀土元素可以大大提高年产量。例 如在初䡉机中軒鋼时, 只要在 SAE 1020 低碳鋼中加入 $0.1 \%$ 的稀土元素, 就可以大大地簡化技术加工过程, 扶减少修整和最后軋制时的損耗; 使年产量增加 $4.2 \%$ (見表 2)。

表 2 稀土元素对軋制SAE 1020 低碳鋼的影响

\begin{tabular}{|c|c|c|c|c|c|c|}
\hline 加 & I & 过 & 程 & 溳 量住 & 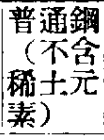 & 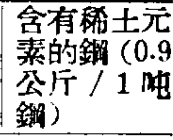 \\
\hline \multicolumn{4}{|c|}{ 1. 銅鋜面量 } & 公厅 & 3600 & 3600 \\
\hline \multicolumn{7}{|c|}{ 2. 大銅坏臬量 } \\
\hline \multicolumn{4}{|c|}{ a. 修整以前 } & 公厅 & 3550 & 值接䡉成 \\
\hline \multicolumn{4}{|c|}{ 6. 修整以后 } & 公厅 & 3240 & \} 中鋼坏 \\
\hline \multicolumn{7}{|c|}{ 3. 中鋼坯产量 } \\
\hline \multicolumn{4}{|c|}{ a. 修整以前 } & 公厅 & 3210 & 3340 \\
\hline \multicolumn{4}{|c|}{ 6. 修整以后 } & 公厅 & 2950 & 3240 \\
\hline \multicolumn{7}{|c|}{ 4. 軋制到最后尺寸 } \\
\hline \multicolumn{4}{|c|}{ a. 修整以前的重量 } & 会厅 & 2925 & 3136 \\
\hline \multicolumn{4}{|c|}{ б. 修整以后的宜量 } & 公厅 & 2810 & 2960 \\
\hline \multicolumn{4}{|c|}{ 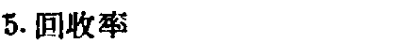 } & $\%$ & 78 & 82.2 \\
\hline
\end{tabular}

注: SAE1020 銅含有下列成分:

碳: $0.18-0.23 \%$; 鉛: $0.30-0.60 \%$;

磷: $0.040 \%$; 硫: $0.050 \%$ 。

加入稀土元素 $0.01-0.03 \%$, 可以大大改善結构

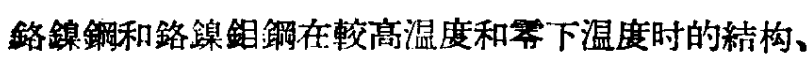

可塑性、冲击咖度以及其他特性。

加入稀士元素对籍鋼起良好作用。它大大地提高 鉻䤼鋼“䤼鉻合金”（䤼 80\%，鉻 20\%）的而热性，使 它在高温情况下的使用时閒延长許多倍，还可提高含 鉻和釦的高电阻鉄合金（費何拉里合金）的强度和防 銹性。加稀土元素还可使各种不銹銅的勒性及液态流 动性提高, 改善加热情况下的可变形性，从而使机械 加工的温度氾圄增大, 改善焊接性。

加入 $0.1-0.2 \%$ 稀土元素可以消灭含有 $19-21 \%$ 鉻和10-12\%䤼, 22-24\%鉻和12-15\%䤼, $24-26 \%$ 鉻和 $19-22 \%$ 䤼, $16-18 \%$ 鉻, 10-14\%䤼和 $2-3 \%$ 䤧 的各种奥氏体合金鋼的先天热脆性，因此大大地改进 了奧氏体鋼的軋制（在某些情况下，其可鍛性是很好

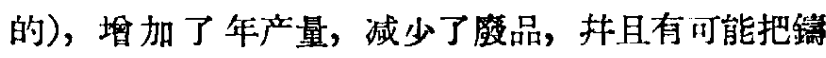
錠的重量从 4 吨增加到 20 吨。加入稀土元素, 可以使 某些型号的不銹鋼大大地改进在高温下的可鋁性，从 而使極大的鑄錠都有可能在初䡉机中进行䡉制。

一般仅仅用于鑄造的鉻䤼錩鋼，在加入稀土元素 后完全可以变成鉔件。創造了一种新型的妨銹銅（鉻 $20 \%$ 、䤼 $29 \%$ 、䤧 $2 \%$ 、銅 $3 \%$ 及稀土元素), 可以用 这种錀制鋼片、鋼条、扁銅、鋼管，甚至鋼絲。

加入稀土元素可以大大提高强度, 抹可以改良含 氮 $(21-12 \mathrm{~N})$ 的閂門鉻䤼鋼在高温时的可政性; 現在 用这种鋼模压制品已事無困难。

現在談一下炼制装甲鋼时稀土元素的应用。

1953-1954 年, 美国試驗生产了 700,000 吨加有 稀土元素的鋼，特別是在 1954 年, 各个治金公司为了 进一步地进行試驗工作，大大增加了稀土元素的訂貨。 此后，美国一个很大的炼鋼公司在熔炼含有碳 0.13$0.28 \%$ 的各种型号的鋼时, 就开始經常采用稀土元素。

稀土元素加入料的价格相当高, 显然这仍是阻碍 發展的因素，虽然在最近几年来价格已有显著的下降。 炼鋼时稀士元素的大規模应用，特別是熔炼低碳鋼和 中碳銅，需要稀士元素价格的进一步下降。如果稀土 元素的价格下降，美国每年用三万吨稀土元素塔炼 4-5 千万吨龬是可以想像的。

稀土元素在炼鐝中的应用可以节省燃料和劳动 力, 增加产品的产量, 降低其价格, 此外, 还可以减 少鎾和䤼的消耗量。在某些情况下, 大約 0.9 公斤稀土 元素可以有效地代替 20 公斤䤼, 而加入 1 公斤稀土元 素可把鎾的含量从 $0.8 \%$ 减少到 $0.4 \%$, 亦即每吨鋼减少

[1] 混合稀土合金一一其中所含各种稀土金的比例 与天然矿石中各种稀土元掌的比例一样。

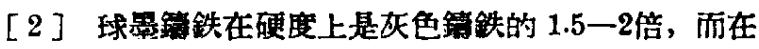
其机械性能上是灰色箭鉄的 2-2.5 倍。它的許多特性, 接 近于合金銅。在許多具要产品的生产.上用它来代替鋼是非常 好的。 


\section{4公厅。}

在美国，炼鋼时使用稀土元素被評价为最近 50 年 来在制合金銅方面最卓越的成就之一。这方面的工作 不仅私人公司在进行，而且政府也在进行着。

对于有色金鳳与合金的冶炼，稀土元素的利用目 前还不显著。这主要首先可能是因为这方面的研究工

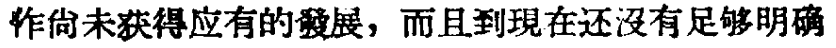
的目的。

苏联在銅、青銅及其他有色金屬和合金的变形处 理方面的經驗是值得注意的。苏联經驗表明，加入少 量的稀土元素就可以很好地中和鈊鉛混合物的有害影 响。因之不仅有可能改良上述材料性質，特別是消灭 其热脆性, 而且还为加工和充分利用次等的和劣等的 金屬开辟了道路。

在希特勄德国, 制造了 4 种由鋁与稀土元素以及

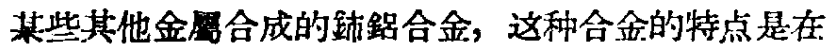
高温下具有良好的强度和可螘性。用这种合金可以制 造內燃机的汽缸曲軸箱、汽缸盖及汽缸座, 以及其他另 件。在英国規定了两种加有少量稀土元素的鋁基合金 的标准。在美国刊物上地談到了飞机發动机活塞用的 加有 $0.05-0.3 \%$ 稀士元素的鋁銅矽合金和鋁鈵合金。 制成了含有 $11 \%$ 稀土元素的新的耐热鋁合金，这种合 金的特点是, 在 $350^{\circ}$ 以上的温度具有非常好的机械性 能。

以上所举的合金都是供飞机制造用的。为了这一 目的，含有稀土元素的鋘合金愈来䇗重要了。英国和 美国規定了含 $1.25-4.0 \%$ 稀士元素、扭且还含鋯和

（或）和和鋁的 8 种鎂合金的标准。它們的成分如表 3 所示。这些合金在較高的温度 $\left(200-315^{\circ}\right)$ 下，都有 很大的强度和抗蠕变的稳定性。在制造哗气式飞机的 动机机身以及操程装置（机体另件、操縱舵、起 落架、輪、祭燒箱、扩散器等) 时可加以采用。在一

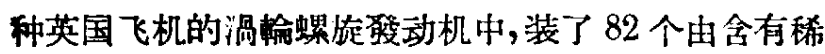

表 3 英国及美国所生产的含鋯及稀土 元素的鎂造合金的化学成分

\begin{tabular}{l|c|c|c|c}
\hline 合金 & & 鋅 & 䖝 & 稀土元素 \\
\hline$Z R E-1$ & 英国 & $2.5-3.5$ & $0.6-0.75$ & $2.5-4.0$ \\
$Z R E-0$ & 英国 & 0.5 & $0.6-0.7$ & $2.5-3.0$ \\
$R Z 5$ & 英国 & $4.0-4.5$ & 0.7 & $1.25-1.3$ \\
$M C Z$ & 英国 & - & 0.6 & $2.5-3.0$ \\
$E Z 33 A$ & 美国 & 3.0 & 0.7 & 3.0 \\
$E K 31 A$ & 美国 & - & 0.55 & 3.0 \\
$E K 30 A$ & 美国 & - & 0.25 & 3.0 \\
$E K 31 D$ & 英国 & - & 0.55 & $2.0(*)$ \\
\hline
\end{tabular}

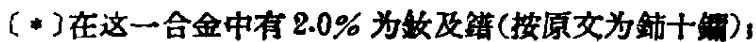

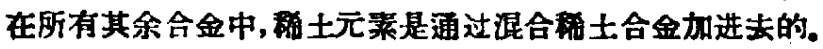

土元素及鋯的 ZRE1 鋘合金制成的䥄件。

含有稀土元素及鋯的变形鎂合金在温度 250$300^{\circ}$ 下具有高度的抗震变性, 此外, 它們还有可㙟性 和良好的可鍤性。其用途是制造飞机机身和飞机婈动 机的另件。

德国在战时采用过会有 $5 \% 、 6 \%$ 及 $10 \%$ 的稀士 元素的鎂銛合金，用它可以制造許多鏗浩的和錆造的 飞机弹动机的活寒。

美国的研究工作泟正明，加入钕和鉝，特别是釹， 对鎂合金的作用特別有利。

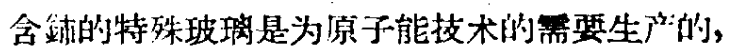
这种玻琌的特点是抗幅射作用的稳定性非常好。它在 放射性幅射的作用下完全不会变黑，因此，对运憸上 用的原子装置的反应器有特殊的价值。从文献山好可 以断定，任何其他的加入料都不能保征得到这样性留

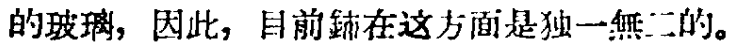

已知的吸收热中子能力最高的它素有六种, 前四

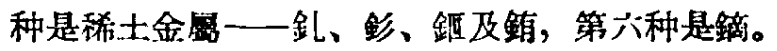

釯的热中子吸收截面大于鎘 18 倍, 大于矹 60 倍, 由于这个特性, 它占有着非常重要的地位。釓及其他 稀土元素的氧化物的吸收能力也是極高的。

在原子反应器中，用釓、钐、銪进行控制（控制杆 及事故防护）和把它們应用于防护材料中都是極有效 的。英国于 1956 年合在㮃䜌进行这一方面的工作。 釔及其化合物作为飞机和潛水艇里原子核装犆中的中 子吸收剂是有很大前途的，因为在飞机和潛水艇里， 减少重量及体积是特品重要的。含有转的金闻陶瓷材 料已經成功地来制造原子核过程的控制杯。

含有剑和其他稀土金虫氧化物的玻琌，吸收热中 子的截面很大; 而含鈰的耐火材料的特点是吸收系数 很呧, 这也是很有兴趣的。

根据放射性輻射能直接轉变为电能的原理可以用 放射性同位素鍶 -90 -釷-90制造耐久的原子能电池。 它的使用斯限为 25 年.

在 1957 年, 用放射性闹位素銿 -147 秥合燐光剂 （磷）及光电管建立了小型的原子能电池。在这个电 池中, 放射性輻射轉变为电流。特别重要的是, 在这 种情况下需要極简单的保护套。这种橔小的电池目前

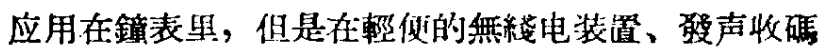
器和操縱装置中使用䤧 -147 显得更为重要。

原子能技术需要具有特殊性質的特殊陶瓷和的火 材料。需要加紧寻找这样的材料, 因此对針、鍄以及 部多其他稀土元素的化合物应該加以注意。

釷、鈰、铺、钢、鈧和釯等的同位素是在探伤技 木、医学以及科学研究工作中可以采用的放射性物

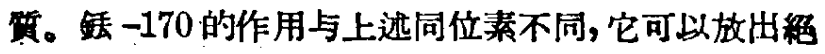


对稳定的、和 $\mathrm{X}$-射棧相似的軟 $\gamma$ 一射戥。一般为了得到 抹运用 X一射线，需要有带輔助設备的、复杂笨重的装 置, 要有喑室, 要有专門的技术人員, 还一定要有电

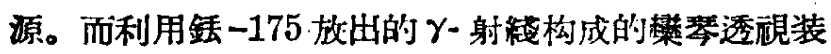
置和一般X-射綫的装置不同, 它非常簡单、輕便, 不 需要有固定的設备和电力供应。根据文献，一种这样 的仪器, 总重仅三公斤左右, 可以由一个人放在背洘 里搬来搬去, 在任何情况下都能够汛速进行工作。也 有一种比較复杂的这类装置（重达 16 公斤），但地是 完全可以携带的。

对于战伤外科以及在造远的、隔䋓的、汥有电的 村和其他居民点来說, 瑟透視装置的意义是不 可估量的; 無疑的, 在火城市的医学工作上世，将应用 这种装置。此外，完全可以用銆 -170 来对輕金鹰和合 金制品、重金屬精細制品进行热伤以及作其他用途。 可以預計，鉣射皎置和电子加强装置的結合，可以 得到高对比性的像 (对比度提高几百倍), 特別是这个 方法还可能用作疾病的早期訩断。

混合稀土和某些稀士元素（如鎌、銅、釹、鏡等） 的氧化物以及許多其它化合物，已經或者可能用于玻 琌工業中，作为覑料、玻璃褪色剂和磨料，在制造特 种玻唡和使玻琌具有对光敏感的性筫方面, 也使用上 述稀土化合物。

䤲、铜、敛、錯及其化合物都能使瓷器和玻琌具 有各种不同的顏色。同时，还可以使玻琌具有各种極 美丽的色朵，成功地雨于制造各种艺术装飾品。用稀 土上色的工業玻璃, 对鉄道运輸是很主要的(加强信号 灯的紅、黄、線等顏色), 还可以用它作为有重要用途 的滤光器。

以不同比例单独地或者混合使用鈃、铰、鉝的产 化物，可以使玻璃袚色抹增加玻琌的透明度。在这方 面如果使用稀土, 就可以降低对玻璃嘘料的原始組分 和耐火材料的要求, 可以不必要进行原料的特殊选矿 手縓，从而在根本改进制品質量力面可以大大节省資 金。二氧化鈰是一种使玻璃褪色的良好材料, 即使在 强烈輻射或在日光长时間作用下，它也能保証玻唡有 高度的固定的透光度。

用稀土可以生产出各种专門用途的玻琌：透紅外 桡玻琌、吸收紫外綫玻璃、酎酸和耐热玻琌、河X-射 戥玻璃、具有特殊光学性能的玻璃。这些玻璃实际上 已經用作 X-射綫滤光器、墨鏡、焊接工人和吹牫璃工 人用的眼篭、其他各种防护玻璃、化学用玻璃、各种 光学仪器, 特別是要保証像的高度准确的潛望鏡、空中 摄影装置及摄影鏡头等用的玻璃。

含有稀土的玻琌对包装食品很有价值, 它可以消 除能引起食品窗坏的光化学反应。这里还要指出, 利
用鈰吸收紫外的能力来防止新料、鮫料及其他許 物資的褀色是極有現实意义的。

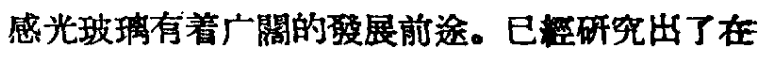
感光玻璃上印像的方法。把感光玻瑀用在彩色电視管 的制造也是很可能的。这种彩色电悓管內有几千个根 据准确的尺寸讲在固定的角度䥷第的小孔。如果用已 知的方法把普通玻唡鑽出这样許多小孔几乎是不可能 的, 但是用酸可以把感光玻㵝“䤮出”这样的小孔。

稀土颜料已在世界玻㻦工業中得到公認。它是 最好的磨光材料，能保証大大加速䀧光过程（加速到 1.5一2 倍), 保証加工表面有很谪量, 而且可以减少 費用。

目前几乎所有的光学玻璃（特別是眼鏡、电視收 音机和貴重仪器用的玻璃)、鏡面玻璃以及汽車上用

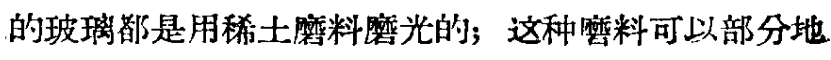
用作磨光花崗石及宝石之用，

苏联的研究及工厂实踐的成果充分詿明稀土蹨料 的質量很高，用在生产上有良好的經济效果。

銥、鐦和鐏的氧化物和其他化合物是盗婇和搪姿 的組成成分。

在照相技术方面也把稀士用作碳电極引火烃的組 成成分和用作㙁光体。

稀土, 主要是稀土的氧化物, 也是䞍热碳电弧以 及高强度电弧陽極引火物的成分。这样就能保証有接 近日光一样的光完度, 發光的效慗高, 光糐的色澤好, 而且每盖灯可有最大的强度。

含有稀土的碳电極可用在强光的高空探照灯、朗 疗灯、电影摄影机和放映机以及电視等。在彩色电影 方面, 特別么泛地采用着这种含稀土的碳电極, 这不. 仅是由于所生的电弧有很高的亮度, 而且由于它的光 譄組成能保証有很好的發光。

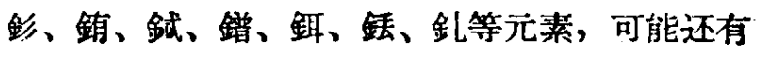
玫元素, 都是結晶磷的活化剂, 而釷、锶、鋅等元素 則是某些工業部門用的增光体的主要組成成分。用稀. 土金屬所活化的閃光燐, 能够在长时間內 $(2-3$ 个月) 储藏和保存大量光能, 然后再放出光来, 这种閃光燐 对紅外綫也有巨大的感光性。

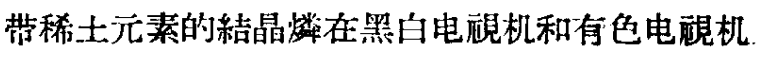
的电子显微管、無綫电测位装疽的放射性电子管、高 压水銀灯、日光灯和示波器等方面都得到运用, 为了 显出不可見的紫外綫和紅外綘, 也在陰極增光体方面 运用。

在电子学和無絞电技术方面, 稀士元素用来作为 吸气剂 (真空管里的除气剂) 和放射体 (陰極叙展)。

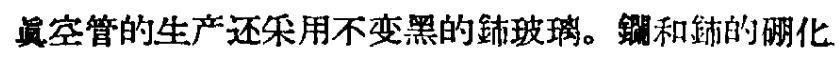
物具有較低的功能, 可能成为电子学中有谷的化合 
物。

含鉄以及其他元素的稀士金會合金具有良好的遇 富气即自燃的性能, 早已用它来制造电光彈和照明彈, 也可以用来制造燒夷彈的“㨏石”（第一次世界大战普 遍使用过)。这种 “軍用火柴” 在第二次世界大战中大 量使用过，而有很多国家在和平时期也在采用。

稀土元素在有机过程和無机过程中作为催化剂 （例如氮的合成和氧化、瞈水、脫筑、卤化、甲醇的合成、 聚合作用、石油原油的热裂、费休一特罗潑稀法間接氩 化制造液体然料等）占有一定的地位。我們很希筀在 石油裂化、合成程稚以及料的过程中能用上述物質 作催化剂。

其他用稀土元素的部閏还有：摄影、鞀皮、制蒜、 煤涑和煤气灯用的紗罩（适用于目前汥有电的边远居 住地区）和印刷用的油墨等。稀土元素的微量元素吧 料可能很有前途。在紡穖工業部門用稀土元素作为媒 染剂，它們还能使紡織品具有耐水和防窗的性能。

必須指出，美国有一家公司䍩常把稀土元素产品 送到炸新工厂去的事实。

釯元素是少有的天然鉄磁材料中的一种，而鉄、 箱、釔、釬、鐵等是最有力的順磁性元素。可以預計 到，在䂭鉄物筫方面的新成就是和上述几种金算元素 的采用分不开的。

在耐火金盗熔化的情况下，稀土金閏的氧化物。 碳化物、氮化物、硫化物以及其他化合物作为高度酎 火材料在噴气技术方面，具有远大的前途。現在弡現 有可能从多种金蜀的鋪酸盐中取得电介質。稀土元素 的氢化物和喼化物方面的工作正在积極开展。已經确 定鈧、釷和銅等元素然燒时能放出大量的热能。

1945 -1955 年, 墢表了将近 8,000 篇有关稀土元 素的化学、物理、冶金学等方面的科学研究著作。特 别是对于个別稀土金属的研究工作正在大力开展。因 此，在进一步扩大稀士元素在工業上的利用这方面， 預计在最短期內将会有言年多新㹲現。

\section{〔本刊特稿 周 航 䚾發斌譯〕}

[1] И. Я. Башилов, Родкио элөменты и их использование, М. 1930.

[2] Доклапы Акадөмии наук СССР, 1937, № 5, с. 261-263; 1940, № 5, c.473-476, c. 783-801; 1941, № 9, c.666-667, c.668-669; 1956, № 2, c.230-232;1956, № 3, c.402-404; 1956, № 4, c. 615-618.

[3] Журнал общей химии, 1956, № 2, с. 379-381, 382-384.

[4] П. И. Китайгородский, Стөкло и стекловарение, М, Промстройиздат, 1950 , с. $54,57,58,74,312-$ 313.

[5] Э. П. Либмач, Редкие зомли, Сория “Трөбования примышлөнности к качөству минөрального сырья", ВИМС, вып. 51, Гостеолиздат, М.-Л., 1948, 50 стр.

[6] Б. Г. Лившиц. Физичоские свойства металлов и сплавов, Мачггиз, М, 1956, 350 стр.

[7] Неуч: а-технический инфоғмационный бюллөтөньВсесоюзного научно-исследовательского института стекла, 1949, № 2, с. 65-66; 1954, № 9, с. $37-54 ; 1954$, № 10 , с. $26-43 ; 1956$, № $1-2$, c. $3-9$, $66-74 ; 1956$, № 3 , c. $49-68 ; 1956$, № 4. c. 3-13.

[8] Огнеупоры, 1956 , № 3, с. 122-125.

[9] Оптика в всенном дөлө, Сб. статөй под рөд. акад. С. И. Вавилова и проф. М. В. Савостьяновой, Т. ПІ, изд. АН СССР, М-Л, 1948. с. 328-376.

[10] Оптико-механическая промышлөнность, 1956, N6 2 , с. $38-41,42-51,77,79$.

[11] Применөние радиоактивных изотопов в промышленности, медицине и сөльском хозяйстве, Доклады иностранных ученых на мөждународной конференции по мирному использованию атомной энергии, Женева, 1955. АН СССР, М, 1956.

[12] П. Прингсгейм Флуорөсценция и фосфоресцениия, ИЛ, М, 1951, 672 стр.

[13] Проблемы совремөнной металлургии, 1954, № 6, 124-133; 1955, № 6 , c. $86-100 ; 1956$, №1, c. $107-$ 119; № 3, с. $76-89$.

[14] Проблөмы соврөменной физики, 1957, № 1, р. 2843, 65-73, 107-129.

[15] Сөссия Акалемии наук СССР по мирному использованию атомной энергии, 1-5 июня $1955 \mathrm{r}$. АН CCCP, M, 1955.

[16] М. П. Спавинский, Физико-химическно свойства элөментов, Металлургиздат, М, 1952.

[17] Справочная книга по светотөхнике, т. 1. АН CCCP. M, 1956 , c. $20-21$, 225-288, 335-442, 443469 .

[18] Стекло, Сб. рефоратов Всөсоюзного научно-исслөдоватөльского института сиөкла, 1956, № 6, c. $26-27$, № 10 , c. $26-30$; № 11 , с. $35-40$; № 12 , c. $6-9$.

[19] Е. А. Терентьева Редкозөмельные элементы. Природа, 1952, № 4, с. 71-81; 1954, № 7, с. 9596.

[20] В. А. Унковская Редкио зөмли и торий, Нерудные ископәөмые, т. П, 1937, с. 457-480.

[21] Успехи химии, 1956, №2, с. 190-241.

[22] Г. М. Фельдман Сырьөвыө рөсурсы рөдких мөталлов эа границей и их использование, Металлургиздат, М, 1940, с. 129-138.

[23] Химия и технология силикатов, 1956, № 2, с. 54-74; № 3, c. 44-54; № 3, с. 90-98; № 4, с. 7189.

[24] Цветныо металлы, 1956, 스 4, с. 94-96, 1956, 스 7, c. $68-72$. 
[25] М. К. Юди Редкозөмельные элементы, В кн. "Ядерные реакторы. Ш. Матөриалы для ядерных рөакторов", И. Л., М, 1956, с. 183-193.

[26] C. S. Acharya, Processing of monazite, Bull. Contr. Electrochem. Res. Inst., 1955, v. 2, No. 1, p. 20-23.

[27] Accessibility of Strategic and critical materials to the United States in time of war and for our expanding economy, Report No. 1627, Washington, 1954, p. 112.

[28] K. S. Blaskett and S. B. Hudson Recovery of monazite concentrate from beach sand from Swansen, N. S. W., Ore dressing investigations, Report No. 515, Melbourne, Dec. 1955.

[29] Canadian Min. J., 1955 v. 76, No. 7, p. 64-65; 1955 , v. 76 , No. 8 , p. 116 , 1955 , v. 76 , No. 9 , p. 147 ; 1956 , v. 77 , No. 5, p. 70-72.

[30] Canadian Min. Met. Bulletin, 1955, v. 48, No. 522 , p. $689 ; 1956$, v. 49 , No. 525 , p. $16-19$.

[31] Ceramic Industry, 1943, v. 40, No. 3, p. 37-38; 1947 , v. 48 , No. 1 , p. $62-130$; 1956 , v. 66 , No. 1 p. 66-69, 96, 109.

[32] Chemical and Engineering News, 1956, v. 34, No. 1, p. 80 ; No. 2, p. 241 ; No. 3, p. 295; No. 6 , p. $550-552$; No. 9 , p. 954 ; No. 10 , p. 1134 ; No. 11 , p. 1165; No. 12, p. 1351; No. 14, p. 1575; No. 15, p. 1706, 1726; No. 20, p. 2396; No 22,p. 2694; No. 23, p. 2822; No. 27 , p. 3231 ; No. 28 , p. 3338 , 3346; No. 29, p. 3442-3445, 3446-3448, 3513; No. 30, p. 3577; No. 32, p. 3808; No. 33, p. 3957; No. 38, p. 4509; No. 45, p. 5434, 5485; No. 46, p. 5496 ; No. 50, p. 6116, 6118, 6138; No. 53, p. $6362-6367,6420$; 1957, v. 35, No. 1, p. 38-40, 94; No. 2, p. 35, 78; No. 5, p. 54.

[33] Colonial Geol, and Min. Resources, 1955, v. 5, No. 1, p. 75-77.

[34] Economic Geology 1954, v. 49, No. 1, p. 119-120; 1956, v. 51, p. 115, 123.

[35] Encyclophedia for chemical technology, 1953, v. 3 , p. 642 ; v. 11 , p. 505 , 514-520.

[36] Engineering and Min. J., 1954, v. 155, No. 3, p. $190 ; 1955$, v. 156 , No. 2, p. $106 ; 1956$, v. 157 , No. 3, p. 106, 111, 198-202.

[37] Glass Industry, 1953, v. 34, No. 2, p. 65-69; 1953, v. No. 4 , p. $199-201 ; 1956$, v. 37 , No. 3 , p. $146-$ 153, 158, 160, 164.

[38] Industrial Engineering Chemistry, 1953, v. 45, No. 1, p. $27 \mathrm{~A}, 29 \mathrm{~A} ; 1954$, v. 46 , No. 12 , p. $15 \mathrm{~A}$ $17 A ; 1955$, v. 47 , No. 2 , p. $9 A-13 A$; 1956 , v. 48 , No.5, p. $43 A$.

[39] Iron Age, 1951, v. 171, No. 23, p. 148-149; 1952, v. 169 , No. 3 , p. $102-105$; 1952, v. 169 , No. 17 . p. $129-134,1952$, v. 169 , No. 18 , p. $140-143$; 1953 , v. 171 , No. 25 , p. $149-153$; 1955 , v. 175 , No. 21 , p. $103-106$; 1956 , v. 178 , No. 18 , p. $98-101$.

[40] Iron and Coal Trades Review, 1955, v. 171, No. 4, p. 551-558; 1956, v. 172, No. 4585, p. 304.

[41] H. E. Kremers, Rare earth metals, Rare metals. Handbook, N.-Y., 1954, p. 329-346.

[42] Light Metals, 1951, v. 14, No. 159, p. 329-334; 1954 , v. 17 , No. 193 , p. $119-127$; 1956, v. 19 , No. 218, p. $135-137$.

[43] Materials and Methods, 1956, v. 43, No. 2. p. 96 $98 ; 1956$, v. 43 , No. 3 , p. $114-117 ; 1956$, v. 44 , No. 4 , p. 26 .

[44] Metal Progress, 1954, v. 66, No. 4, p. 115-119.

[45] Mines Magazine, 1953, v. 43, No. 9, p. 30-31; 19 54, v. 44, No. 2, 29, 51 .

[46] Minerals Yearbook 1943, p. 821 ; 1945, p. 15841585 ; 1950 , p. $1323-1325$; p. 1354-1355; 1951, p 1361-1363.

[47] Mining Congress J., 1955, v. 41, No. 10, p. 81 .

[48] Mining Engineering, 1954, v. 6, No. 3, p. 267; 1955 , v. 7 , No. 8 , p. 742-746.

[49] Mining Journal, 1948, v. 230, No. 5880, p. 316; 1951, v. 237, No. 6048, p. 59; 1954, Ann. Rev., p. $59,129,169 ; 1955$, v. $244 ; 1954$, v. 243, No. 6205 , p. $96-97$; No. 6206 , p. $130-131$, No. 6207 , p. 158-159; 1955, Ann. Rev., p. 55, 57, 137, 139, 140, $141,180,197,198 ; 1956$, v. 245 , No. 6266, p. 349; No. 6257, p. 102-103.

[50] Mining World, 1954 , v. 16, No. 2, p. 26-30; 1956, v. 18 , No. 1 , p. $43-45$.

[51] R. D. Nininger, Minerals for atomic energy, Toronto, N.-Y., L., 1954.

[52] Nucleonics, 1952 , v. 10, No. 11, p. 52-55; 1953 , v. 11, No, 2. p. $29 ; 1954$, v. 12 , No. 5, p. 35-37; 1954 , v. 12 , No. 7 , p. 82 ; 1955 , v. 13 , No. 12 , p. 57 ; 1957 , v. 15, No. 1, p. 44-46.

[53] Physical Review, 1954, v. 94, No. 5, p. 1140-1142; 1955 , v. 98 , No. 2, p. 426-431; 1955 , v. 100 , No. 6, p. 1595-1596.

[54] J. C. Olson, S. R. Wallace, A contribution to economic geology, Thor:um and rare-earth minerals in the Powderhorn district, Gunnison county, . Colorado-Geol. Survey Bull. No. 1027, 1956, p. 693-694.

[55] Science, 1954, v. 119, No. 3088, p. 325-326.

[56] South Agrican Min. Eng. J., 1953, v. 64, No. 31 64, p.171; 1956, v. 66, No. 3283, p. 825 .

[57] R. C. Vickery, Chemistry of the lanthanous, New. York, Acad. press, 1953, 296 pp. 